\title{
Framework for developing a new model of risk classification according to the energy usage of companies
}

\author{
Ana ȘERBĂNESCU \\ The Bucharest University of Economic Studies, Bucharest, Romania \\ Ana_Serbanescu@Hotmail.Com \\ Michael KRUTWIG \\ The Bucharest University of Economic Studies, Bucharest, Romania \\ Michael@Krutwig.Com
}

PICBE |

1150

\begin{abstract}
In the last 50 years, both the authorities and the majority of the citizens have understood the need to enforce measures to both preserve energy and reduce the costs of producing it. Nowadays, every developed country has correlated the profitability and the competitiveness of its industry with the efficient and sustainable use of energy and is therefore making conscious efforts to improve these areas. Any action program deemed to enhance energy efficiency has as main component the critical analysis of the energetic resources allocated to an activity in a given perimeter, also known as energy audit. This paper aims to develop a model of risk classification to be applied in planning and performing procedures during energy audit, which can allow a common framework to be developed in this area of audit. The stakeholders of the entity will also be offered a unitary perspective regarding the risks of the respective business, which can be helpful in their decision-making process. The research methodology of this paper consists of quantitative instruments, namely the statistical analysis of a database containing energy audit conclusions of companies in Europe. The indicators used will relate to energy savings, the number of measures implemented as a result of the audit, the percentage of energy saved from total consumption (energy efficiency) and the business line of the company. The novelty this framework will bring consists of the congruence created in the energy audit procedures of different practices and of the standardization and quality improvement in energy audit opinions. The approach of energy audits will therefore evolve towards a risk based one, rather than an analytical one. Also, we will explain the importance of energy savings for the profitability and the competitiveness of companies in the economy today, while facilitating a transparent communication with the stakeholders. This analysis is relevant especially given the fact that the cycle of 4 years after the directive of mandatory energy audit has been enforced ends with 2018 and a conclusion can be drawn before the new audit period starts in 2019.
\end{abstract}

Keywords: energy, audit, risk, classification, assessment, framework, stakeholders

\section{Introduction}

The aim of this paper is to develop a framework to be used in the risk classification applied in planning and performing procedures during energy audit, which can allow a common approach to be developed in this area of audit. The stakeholders of the entity will also be offered a unitary perspective regarding the risks of the respective business, which can be helpful in their decision-making process. This debate is particularly relevant given the fact that in 2018 the 4-year period after the directive of the EU regarding mandatory energy audits ends and a new audit period will start. Therefore, it is crucial to review the results of this audit cycle 2014-2017, so that they can be used for the following audit period both by the auditors, as well as by the stakeholders of the audit performed. 
In order to achieve this, we have analyzed a population of 1308 audited entities which are mainly SME's, defined by the EU norm 2003/361 as entities with not more than 249 employees and turnover of maximum 50 Mio. EUR.

First, we will define the term energy audit and we will detail the types of audit/consultancy procedures performed for this entities which have provided the results at hand. Subsequently, we will analyze the database and conclude over the framework, if it is suitable to be the basis of a risk assessment model or not.

\section{Literature Review \\ Definition of energy audit}

An energy audit is a comprehensive, systematic review of a company's energy consumption. All energy data is collected and evaluated in terms of efficiency. Among other things, the current energy consumption of buildings or groups of buildings, individual operations or production facilities is checked. In addition, an energy audit may also relate to a private or public service. Behind such systematic analysis is the goal of saving energy and optimizing energy consumption. This provides an important basis for implementing measures to increase energy efficiency and reduce energy costs in companies. The difference with a traditional energy consultancy is, among other things, that the energy audit can only be carried out by consultants accredited BAFA (Bundesamt für Wirtschaft und Ausfuhrkontrolle). Energy audits have the role of accelerating the implementation of energy efficiency measures by informing the clients/beneficiary of the audit about their options and related energy cost savings, in particular. Typically, though only a portion of the measures recommended in audits actually gets implemented (Andersen and Newell 2004, Fleiter et al. 2012). Most evaluations rely on surveys involving respondents' subjective responses. Thus, the estimated effects may suffer from social desirability and other biases. Arguably for lack of data (heterogeneity of measures and companies), no evaluation has so far relied on a comparison with a control group. (Schleich J., 2015)

Nowadays, according to A. Kluczek, P. Olszewski (2017), the energy audit is widely considered as one of the most cost-effective ways to improve energy efficiency. This is done by investigating energy flows within a firm as well as within individual process units (Trianni et al., 2014).

The audit consists of the following process, which is applicable for the directives detailed in the next chapter of this paper:

Energy audits debut with the pre-audit questionnaire, which includes first-hand information about the main processes of the company. The information contained relates to the manufacturing profile, processed materials, final product and production scale, giving auditors hints to possible energy conversion processes. In addition, it includes annual usage and costs (based on monthly utility bills) of electricity, natural gas (or other fuel), water, processed gases (N2, 02, etc.) and eventually information about the most energy intensive machines/processes (Telukdarie et al., 2006). Based on this information, the auditor should have a general image of the factory's energy conversion and flow allowing for identification of areas of possible improvement) (Kluczek A., Olszewski P. 2017)

The next step refers to the initial analysis of processes and includes a kick-off meeting (also followed by multiple eventual understanding meetings) with the engineering team, related the main processes of the entity. The audit team (composed of qualified engineers 
and consultants with experience in the domain) will communicate throughout the process with the operational managers and the engineers of the audited entity. The auditor must also perform walkthrough of the process discussed with the client and observe how the procedures described are also implemented in the daily activity of the company.

In the following audit period, the auditors underline the possible energy savings related activities. The next steps have the purpose to perform the energy assessment according to the methodology used/the directive applied. Auditors request from the client data, documents, measurements, characteristics of manufacturing equipment and processed materials, general energy streams, etc. The information is processed and analysed by the team. Throughout this phase, a continuous communication is maintained with the client in order to insure a proper understanding of the transition from the effective processes to the databases which are processed. (Wittsiepe, R. 2008)

The energy audit report is then prepared in accordance with the information which was collected and processed. The assumptions, procedures performed, as well as the conclusions must be documented and explained to the client in a synthetic manner.

The last stage is represented by the implementation report. The auditor must follow up with the client in order to insure that the proposed measures were implemented, respectively that the observations/recommendations were considered and to assess to which extent this happened.

\section{The purpose of energy audits}

The final objective of the energy audit performed is to formulate observations/ recommend measures regarding the following:

\section{Energy savings}

Energy savings means an amount of saved energy determined by measuring and/or estimating consumption, before and after implementation of an energy efficiency improvement measure, whilst ensuring normalization for external conditions that affect energy consumption. (European Commission, 2016) This indicator results from the process of transforming the resources available in supply for the consumers and is strictly correlated with the energy efficiency, please see the figure below.

Figure 1. Diagram of energy resources and their transformation for consumption

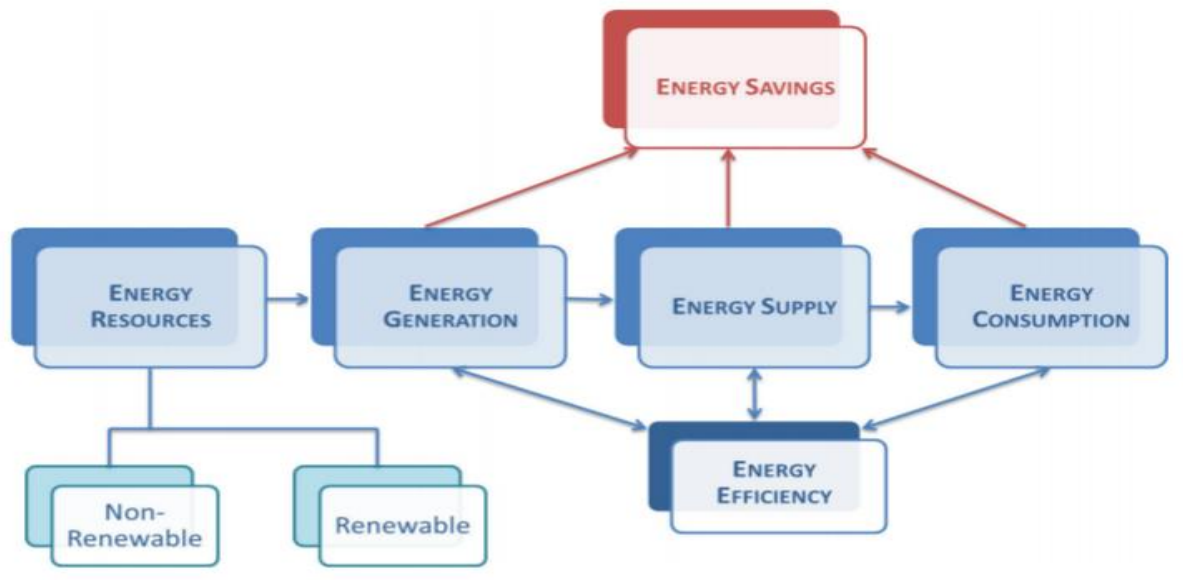

Source: INTOSAI Working Group on Environmental Auditing, Energy Auditing. 


\section{Energy efficiency improvement}

Energy efficiency improvement means an increase in energy efficiency as a result of technological, behavioral and/or economic changes. This is also seen as a strategy of reducing greenhouse gas emissions, but only with the condition of drastically accelerating the process of energy efficiency. (Fleiter T. et. al. 2012)

The EU Energy Efficiency Directives, use the following definition for the term 'energy efficiency', namely: the ratio of output of performance, service, goods or energy, to input of energy. (European Commission, 2015) According to the briefing in October 2015, to illustrate these kinds of output, thermal comfort in a building is an example of performance; transport of persons or of information is a service; a smartphone is a good, the production of which requires energy.

The main benefit of improving energy efficiency for the companies is that by reducing energy usage, energy bills should be reduced for industrial consumers, thereby improving their competiveness. (Erbach G., 2015)

\section{Emission reduction}

Increasing amounts of greenhouse gases (GHGs) in the atmosphere have generated climate change with negative impact on both natural and socio-economic systems. (Hannah, L. 2015). The most significant and fast emissions reductions can be determined by the implementation of energy-efficient technologies. Examples of such are high-efficiency light bulbs, improving energy efficiency of buildings by better insulation techniques but not only. By such changes, the consumer can obtain substantial and fast energy savings by utilization of the existing technology or equipment. Because energy efficient technologies are not widely used, the gains in efficiency can be realized in a numerous variety of existing applications. Improved insulation, energy-efficient windows, and better heating and cooling systems are examples according to Hannah Lee. Because these modifications of existing technologies also represent cost effective methods, for example leading to fuel economies, retrofitting items often result in being either at breakeven as investment, or even managing to yield a profit.

\section{Energy cost reduction}

Cost reduction is directly linked to the energy savings achieved by the audit measures implemented. In many cases, it is simply the product of energy savings and its unit price. The total price may include fuel costs, transmission and distribution system associated costs, weather influence over costing and regulations of the state. (European Commission, 2016). 


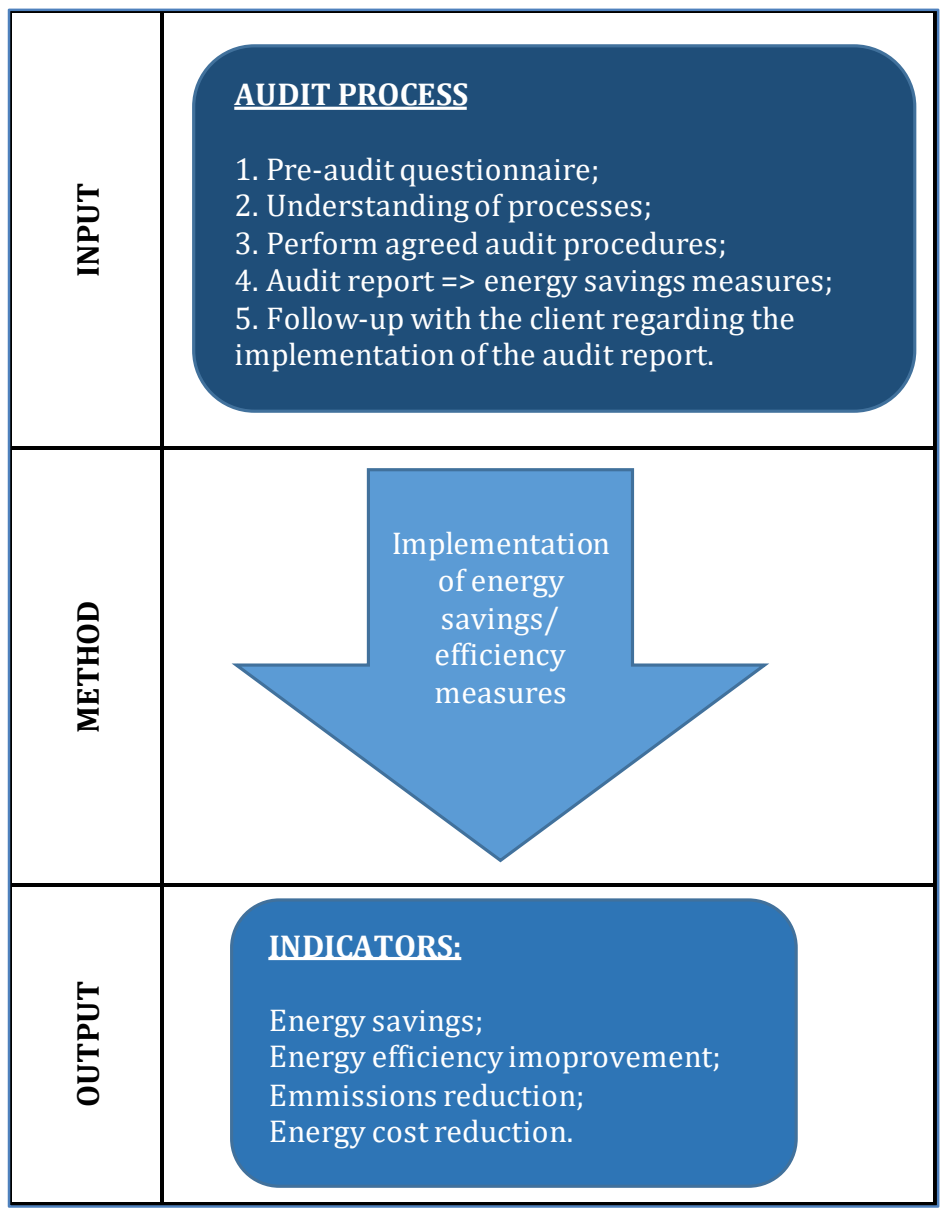

PICBE | 1154

\section{Figure 2. Audit process overview in relation to the results thereof}

Source: Authors' own research. In 2008, a programme was established in Germany to provide grants for energy audits in SMEs. Fleiter et al. (2012) presents the types of energy efficiency measures and the areas fow which they have been proposed by the auditors and implemented: heating and hot water, process heat, compressed air, electric motors and drives, ventilation and air conditioning, lighting, building insulation, waste heat recovery, process technology, ICT, cooling (for processes), energy management, behavior, and other measures.

Furthermore, Mai et al. (2014) further analyzed the implemented measures, and concluded that the majority of findings in the initial energy audits were for lighting, heating and hot water, building insulation, ICT and organizational measures (behavior and energy management). The more complex audits which were conducted would be focused on process heat, process technology, cogeneration, motors, heat recovery, refrigeration and renewable energy. Therefore, the framework presented in this paper aims to split the consumption amount in relevant categories which would take into account the elements generating the discrepancies between different types of audit conducted. 


\section{Methodology}

The qualitative research methodology consisted of reviewing the literature of the research field, as well as the existing legislative frame which represents the context for the future development of the energy audits.

Our first research hypothesis for the framework developed is that a risk assessment model is strictly dependent on the energy consumption levels of the entities activating in a specific industry and should therefore be developed in accordance.

Our second hypothesis is that the possibility to implement measures and to improve energy efficiency is also dependent on the energy consumption levels.

In order to conclude over the research hypothesis, we have analyzed a database of a total of 1308 items representing energy audit results, representing the quantitative research methodology of the paper. The audits were performed for SME companies with the activity based in Germany.

We have considered this population representative for the paper given the fact that Germany's economy is the largest national economy in Europe and the industry is developed and diversified, so that the conclusions can be relevant for the business lines analyzed. We have stratified the population according to the business in which the entities operate, the total energy consumption, the number of findings/measures suggested and the energy saving resulted.

The challenge before using the data provided was that the system did not have reliable information regarding the completeness and correctness of the data collected. Therefore, we have performed a cleansing procedure over the information at hand, which consisted of 2600 energy audit records. This procedure consisted of excluding the following: test companies, companies which did not have a plausible relationship between energy utilized and energy purchased and items which had more than 10 instances from one class of audit procedure type performed.

After this cleansing was performed, we have proceeded to stratify the population. Firstly, we have analyzed the types of audit performed, considering the law/standard which regulated the audit.

\section{Energy audit after DIN EN 16247-1}

Out of the total population, a number of 840 instances analyzed are results of energy audits performed in accordance with DIN EN 16247-1.

The standard EN 16247-1 is a European standard that was also published in October 2012 by the German Institute for Standardization and has since been referred to as A4 EN 16247-1. It sets general consulting requirements and is designed to ensure clarity and transparency in the market. In concrete terms, the standard specifies methods and the systematic conduct of a qualified energy analysis.

In order to achieve the ambitious European and German climate protection goals, the commitment of the economy is needed in addition to the participation and acceptance of the population. That is why the Federal Government has initiated a number of measures to increase energy efficiency in companies. Among other things, the European Energy Efficiency Directive, which requires an energy audit under EN 16247-1 for companies, was transferred into German law and the Energy Services Act, or EDL-G for short, was amended accordingly. 
According to this directive, large companies in particular will have to check their energy consumption by 5 December 2015 by carrying out an energy audit in accordance with the European standard 16247-1. The energy audit must then be repeated regularly, at least every four years. For example, it mandates the amended Energy Services Act, which came into force on 22 April 2015. Alternatively, companies can introduce an ISO 50001 energy management system (EnMS) or an environmental management system (UMS) according to EMAS. This is also the deadline for 5 December 2015. By then, a Memorandum of Understanding on the introduction of an energy or environmental management system must have been signed and a technical stocktaking carried out. Companies have longer time to certify the chosen management system. This must be done by 31 December 2016 at the latest.

The new regulation is therefore, on the one hand, an important step towards implementing the EU Energy Efficiency Directive and, on the other hand, in achieving Germany's energy-saving targets. These energy audits are also important because they lead companies to identify their own energy-saving potential and to invest specifically in energy efficiency measures. In the context of the energy transition, the legislature therefore attaches a decisive role to the energy audits.

\section{Energy consulting for SME s (EBM)}

A number of 432 instances analyzed refer to results of EBM.

Energy consulting must meet the essential requirements for an energy audit within the meaning of Section 8a of the Energy Services and Other Energy Efficiency Measures Act (EDL-G) and, in particular, the requirements of the EN 16247-1. According to this, the use and consumption of energy is systematically investigated and analyzed in a company. The aim is to identify energy flows and potential for energy efficiency improvements. In a further step, the various measures are assessed in a monetary manner by investment/profitability calculations, so that companies can, as a result, record at a glance which investments pay off in which period. The main potential savings and measures are to be summarized in an advisory report. (BAFA, 2017)

\section{Energy audit after ISO 50001EB}

A number of 17 instances analyzed refer to results of ISO 50001 consulting.

The term energy management stands for a systematic energy consumption analysis as well as the subsequent planning and implementation of optimization measures of energy consumption. Monitoring and continuous development of improvement measures is also part of this management area. The ISO 50001 standard sets relevant requirements for the certification of an energy management system (EnMS). If the Energy Management System (EnMS) meets standard requirements, companies can improve their energy efficiency by reducing energy use and reducing both energy-related costs and environmental impacts. In order for companies to benefit from peak compensation under the Electricity and Energy Tax Act, they must have introduced an EnMS.

An EnMS is also a prerequisite for limiting the EEG levy for companies with an annual electricity consumption of $10 \mathrm{GWh}$ or older. In order to be recognized, ISO 50001 certification or registration under EMAS-VO is required. SMEs also have the option of presenting an "alternative system" for peak compensation, such as an energy audit between EN 16247-1 or a system under Annex 2 of the Top Repair Efficiency System Regulation (SpaEfV). With the 
amendment of the Energy Services Act (EDL-G), Article 8 (4) - 7 of the EU Energy Efficiency Directive (RL 2012/27/EU) has been transposed into German law. Article 8 (4) - 7 requires all companies that are not small or medium-sized enterprises (SMEs) to carry out an energy audit until December 2015 and at least every 4 years thereafter. Excluded from this requirement are those companies that have a certified ISO 50001 EnMS or an environmental management system registered under EMAS.

Optimization of technical systems - QSTSO

A number of 19 instances analyzed refer to results of technical systems optimization.

The optimization of technical systems includes all stationary plant or plant parts that contribute to the energy efficiency of cross-sectional technology, by improving their system connectivity. In principle it refers to renewal and acquisition of a complete production facility. Similarly, not considered items under this directive are heat producers. As part of the optimization of technical systems, replacement and expansion investments are eligible in the following cross-sectional technologies: Electric motors and drives, pumps, indoor air systems, compressed air systems, heat recovery. In addition, the reinstallation of the above cross-sectional technologies, including the plant parts required for integration into a technical system, will be encouraged.

After the stratification according to audit type, we have stratified the database of a total of 1308 items according to the business in which the entities operate, the total energy consumption, the number of findings/measures suggested and the energy saving resulted.

Given the fact that according to the laws presented above, the audit/advisory services are mandatory once every four years, we have analyzed the results obtained in the last period which ended in 2017, namely 2014-2017. In total, the population total energy consumption for the observed period (4 years) is of approximately $127,117,319 \mathrm{MWH} /$ year.

The business lines analyzed are detailed in the first column of the figure below, where it is also noticeable; the fact that approximately $36 \%$ of the total consumption is in the manufacturing industry. Due to the fact that also the majority of the findings $(1,508)$ were also presented for this industry, we have considered it the most relevant to be analyzed in order to conclude over our research hypothesis.

Table 1. Population analyzed split by business lines and energy consumption

\begin{tabular}{|llllll|}
\hline & $\begin{array}{l}\text { Total } \\
\text { number of } \\
\text { energy } \\
\text { audit } \\
\text { measures }\end{array}$ & $\begin{array}{l}\text { Total energy } \\
\text { saved after } \\
\text { implementation } \\
\text { of measures } \\
\text { [kWh / a] }\end{array}$ & $\begin{array}{l}\text { Total } \\
\text { consumption } \\
\text { during one year } \\
\text { [kWh] }\end{array}$ & $\begin{array}{l}\text { Weight of } \\
\text { consumption } \\
\text { in total }\end{array}$ & $\begin{array}{l}\text { \% of energy } \\
\text { savings from } \\
\text { total } \\
\text { consumption }\end{array}$ \\
\hline Manufacturing & 1,508 & $1,013,938,127$ & $46,035,786,435$ & $36 \%$ & $2 \%$ \\
\hline Transportation and storage & 158 & $53,847,689$ & $19,151,103,901$ & $15 \%$ & $0 \%$ \\
\hline Healthcare & 480 & $215,436,890$ & $15,092,291,758$ & $12 \%$ & $1 \%$ \\
\hline Energy supply & 96 & $18,606,967$ & $9,006,528,114$ & $7 \%$ & $0 \%$ \\
\hline
\end{tabular}

(continued on the next page)

DOI: 10.2478/picbe-2019-0101,pp. 1150-1161, ISSN 2558-9652| Proceedings of the $13^{\text {th }}$ International Conference on Business Excellence 2019 
Table 1. Population analyzed split by business lines and energy consumption (continued)

\begin{tabular}{|c|c|c|c|c|c|}
\hline Business & $\begin{array}{l}\text { Total } \\
\text { number } \\
\text { of } \\
\text { energy } \\
\text { audit } \\
\text { measure } \\
\text { s }\end{array}$ & $\begin{array}{l}\text { Total energy } \\
\text { saved after } \\
\text { implementatio } \\
\mathrm{n} \text { of measures } \\
\text { [kWh / a] }\end{array}$ & $\begin{array}{l}\text { Total } \\
\text { consumption } \\
\text { during one year } \\
\text { [kWh] }\end{array}$ & $\begin{array}{l}\text { Weight of } \\
\text { consumpt } \\
\text { ion in } \\
\text { total }\end{array}$ & $\begin{array}{l}\% \text { of energy } \\
\text { savings from } \\
\text { total } \\
\text { consumption }\end{array}$ \\
\hline $\begin{array}{l}\text { Finance and insurane } \\
\text { industry }\end{array}$ & 200 & $22,827,695$ & $8,584,924,595$ & $7 \%$ & $0 \%$ \\
\hline $\begin{array}{l}\text { Trade \& service of motor } \\
\text { vehicles }\end{array}$ & 485 & $153,811,657$ & $7,450,517,916$ & $6 \%$ & $2 \%$ \\
\hline $\begin{array}{l}\text { Freelancing, science and } \\
\text { technological services }\end{array}$ & 66 & $1,390,643$ & $3,074,425,777$ & $2 \%$ & $0 \%$ \\
\hline Other services & 188 & $54,873,900$ & $3,041,022,951$ & $2 \%$ & $2 \%$ \\
\hline $\begin{array}{l}\text { Supply of sundry scientific } \\
\text { services }\end{array}$ & 204 & $5,054,369$ & $2,632,971,490$ & $2 \%$ & $0 \%$ \\
\hline Housing & 133 & $9,162,925$ & $2,591,343,287$ & $2 \%$ & $0 \%$ \\
\hline Hospitality/catering & 348 & $74,713,795$ & $2,500,010,750$ & $2 \%$ & $3 \%$ \\
\hline Arts & 138 & $131,982,677$ & $2,312,923,745$ & $2 \%$ & $6 \%$ \\
\hline Construction & 69 & $1,431,598$ & $2,124,110,045$ & $2 \%$ & $0 \%$ \\
\hline $\begin{array}{l}\text { Agriculture, Fisching, } \\
\text { Fischfarming }\end{array}$ & 63 & $8,024,398$ & $1,378,283,914$ & $1 \%$ & $1 \%$ \\
\hline $\begin{array}{l}\text { Information\&communicati } \\
\text { on }\end{array}$ & 81 & $1,579,122$ & $1,061,976,180$ & $1 \%$ & $0 \%$ \\
\hline $\begin{array}{l}\text { Social services, public } \\
\text { administration }\end{array}$ & 37 & 741,714 & $715,092,033$ & $1 \%$ & $0 \%$ \\
\hline Education & 32 & $1,303,679$ & $250,602,809$ & $0 \%$ & $1 \%$ \\
\hline Water supply & 7 & 73,501 & $85,071,227$ & $0 \%$ & $0 \%$ \\
\hline Mining industry & 2 & 50,001 & $28,332,247$ & $0 \%$ & $0 \%$ \\
\hline Total & 4,295 & $1,768,851,347$ & $127,117,319,174$ & $100 \%$ & $1 \%$ \\
\hline
\end{tabular}

Source: Authors' own research.

\section{Results and discussions}

Firstly, the business line was split according to the percentage of energy savings in total consumption of the entity. Out of the total measures proposed, more than $90 \%$ have only generated energy savings of less than 10\%, which means that in the first audit period of 4 years, the measures implemented have not lead to a significant improvement in energy savings. In the chart below, it becomes clear, that in actuality, the majority of the measures 
have only lead to energy savings of less than $1 \%$ for the most significant part of the total energy consumption of the manufacturing companies. Therefore, the need to improve the audit methodology and adapt it to the specific of the industries becomes clear, because otherwise no significant changes are to be expected in the next audit period either.

Table 2. Energy savings buckets (in \%)

\begin{tabular}{|llll|}
$\begin{array}{l}\text { \% of energy savings } \\
\text { from total } \\
\text { consumption (\%) }\end{array}$ & $\begin{array}{l}\text { Sum of total } \\
\text { consumption in } \mathbf{k W h}\end{array}$ & $\begin{array}{l}\text { Number of measures } \\
\text { implemented }\end{array}$ & $\begin{array}{l}\text { Sum of energy savings } \\
\text { /year in } \mathbf{k W h}\end{array}$ \\
\hline$<1 \%$ & $37,552,238,352$ & 989 & $43,999,728$ \\
\hline $1-10 \%$ & $6,471,714,635$ & 418 & $358,682,348$ \\
\hline $11-40 \%$ & $1,511,527,435$ & 71 & $289,034,359$ \\
\hline$>40 \%$ & $500,306,013$ & 30 & $322,221,692$ \\
\hline Grand Total & $\mathbf{4 6 , 0 3 5 , 7 8 6 , 4 3 5}$ & $\mathbf{1 , 5 0 8}$ & $\mathbf{1 , 0 1 3 , 9 3 8 , 1 2 7}$ \\
\hline
\end{tabular}

Figure 3. Illustration of energy savings \% of total consumption in the manufacturing industry

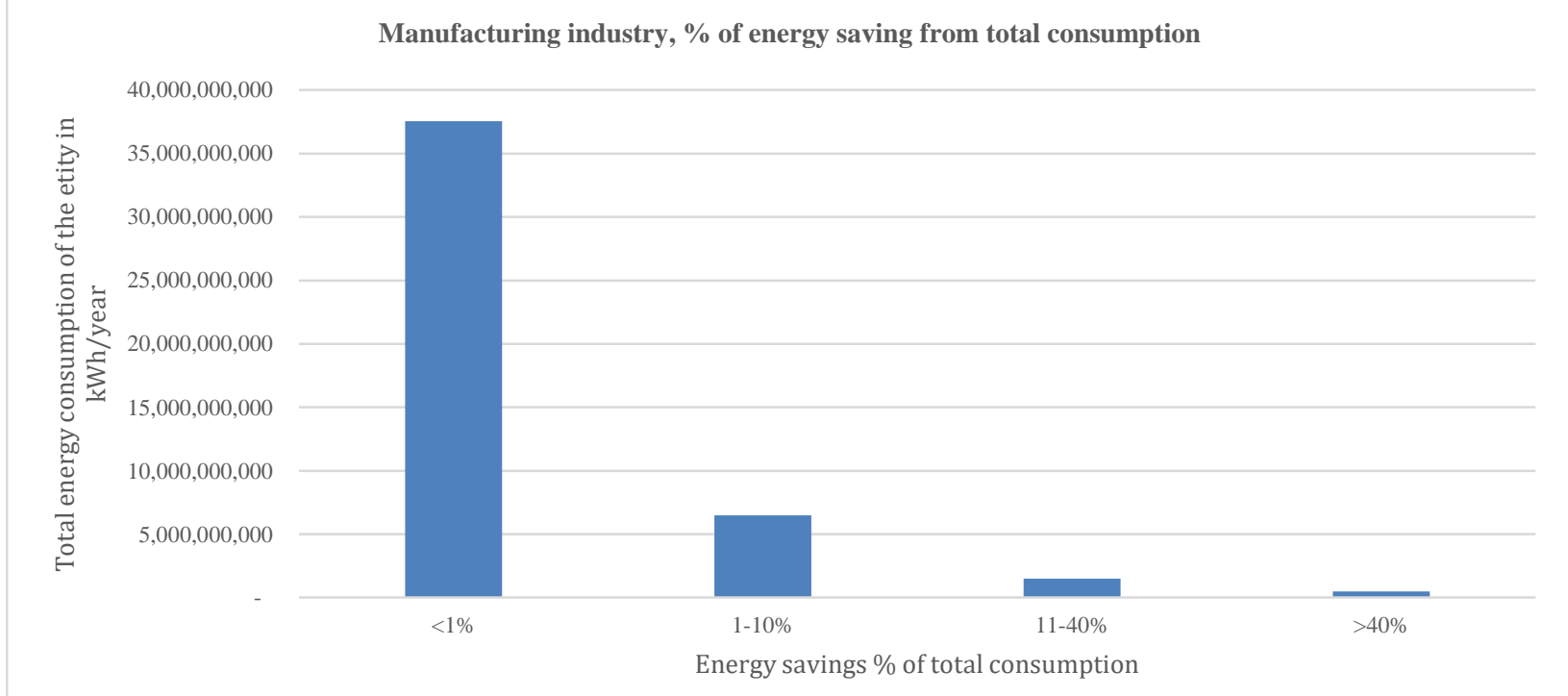

Source: Authors' own research.

Secondly, another relevant split for our research refers to the quartiles of the average total consumption of the companies. We have assumed that according to the size of the entity, the energy consumption increases. Therefore, in order to realize statistically relevant intervals we have considered the 4 quartiles of the total population and added the average energy consumption of the entities according to the upper and lower limits. We have observed that the number of findings of the audit and the measures implemented increase with the size of the companies audited, therefore resulting in more complex processes to be audited. As seen below. In the first quartile of the population, only 1\% of the total average consumption of the companies can be found, therefore we have not considered it relevant for the correlation. Excepting the first quartile, the average energy savings of the consumption increases with the size of the company. It can be assumed that the energy saved increases with the size of the entity. 
Table 3. Average number of audit findings and energy savings \% correlated with average consumption of the entities

\begin{tabular}{|llll|}
\hline $\begin{array}{l}\text { Quartile Intervals } \\
\text { of energy } \\
\text { consumption }\end{array}$ & $\begin{array}{l}\text { Average Total } \\
\text { Consumption in } \mathbf{k W h}\end{array}$ & $\begin{array}{l}\text { Average number of } \\
\text { findings/measures } \\
\text { implemented }\end{array}$ & $\begin{array}{l}\text { Average energy saving } \\
\% \text { of consumption }\end{array}$ \\
\hline Q1 & $5,410,381$ & 3.46 & $4 \%$ \\
\hline Q1-Q2 & $26,757,360$ & 4.18 & $1 \%$ \\
\hline Q2-Q3 & $80,846,216$ & 4.35 & $2 \%$ \\
\hline Q3-Q4 & $399,690,377$ & 4.87 & $3 \%$ \\
\hline
\end{tabular}

PICBE |

\section{Conclusion}

The first research hypothesis - that a risk assessment model is strictly dependent on the energy consumption levels of the entities activating in a specific industry and should therefore be developed in accordance was validated, given the fact that, as seen above, the number of findings increases for every interval of energy consumption level observed.

Our second hypothesis - that the possibility to implement measures and to improve energy efficiency is also dependent on the energy consumption levels, is only partly validated, given the fact that, as seen above, the average energy saving \% of total consumption increases in accordance with the consumption level, but only after a certain threshold of the industry is exceeded. This means other indicators must also be considered in the risk assessment, not only the dimension/consumption level of the entity.

In the next audit period of 4 years, which starts in 2019 , both the audited as well as the audit companies can consider the correlations above in the audit process. In order to develop a risk assessment model for the audit procedures in the upcoming period, the new results can be compared to the correlations in the present framework. By adding other indicators and new relationships, this framework will constitute the starting point for developing a comprehensive risk based approach model to be used by the stakeholders in the industry, as well as by the audit companies in their procedures.

\section{References}

Bundesamt fur Wirtschaft und Ausfuhrkontrolle (2017). Energieberatung im Mittelstand. Retrieved from http://www.bafa.de/DE/Energie/Energieberatung/Energieberatung_Mittelstand/e nergieberatung_mittelstand_node.html

Energiekonsens - die Klimaschützer (2015). Energieaudit nach DIN EN 16247-1. Retrieved from

https://www.energiekonsens.de/media/03_Unternehmen/Themenblaetter/energie audit-gesetz-en-16247-1.pdf

Erbach, G. (2015). Understanding energy efficiency. Briefing of the EPRS / European

Parliamentary Research Service. European Union: EPRS Member's Research Service.

Fleiter, T., Hirzel, S., \& Worrell, E. (2012). The characteristics of energy-efficiency measures - a neglected dimension. Energy Policy, 51, 502-513. 
Fleiter, T., Schleich, J., \& Ravivanpong, P. (2012). Adoption of energy-efficiency measures in SMEs - An empirical analysis based on energy audit data. Energy Policy, 51 (2012), 863-875.0

Hannah, L. (2015). Climate Change Biology. London: Academic Press, Elsevier, 382.

Hirzel, S., Nabitz, L., Wohlfarth, K., Rohde, C., Behling, I., Clarke, D., Perera, N., \& Turner, R. (2016). A Study on Energy Efficiency in Enterprises: Energy Audits and Energy Management Systems. European Union: European Commission, Directorate-General for Energy.

INTOSAI Working Group on Environmental Auditing (2016). Energy Savings. Jakarta, Indonesia, 18.

Kluczek, A., \& Olszewski, P. (2017). Energy audits in industrial processes. Journal of Cleaner Production, 142 (2017), 3437-3453.

Mai, M., Gruber, E., Holländer, E., Roser, A., Gerspacher, A., Fleiter, T., Hirzel, S., Ostrander, B., Schleich, J., \& Schlomann, B. (2014). Evaluation des Förderprogramms „Energieberatung im Mittelstand“. Karlsruhe: IREES GmbH | Fraunhofer ISI.

Schleich, J., Fleiter, T., Hirzel, S., Schlomann, B., Mai, M., \& Gruber, E. (2015). Effect of energy audits on the adoption of energy efficiency measures by small companies. eceee 2015 Summer Study - First Fuel Now, 8-250-15 Schleich et al.

Wittsiepe, R. (2008). IFRS for Small and Medium-Sized Enterprises. Wiesbaden, Germany: Gabler Verlag | Springer Fachmedien Wiesbaden GmbH. 